\title{
Current consensus on clinical features, pathogenesis, diagnosis and management of autism spectrum disorder in children: A brief review
}

\author{
Panda P. ${ }^{1}$ \\ ${ }^{1}$ Dr Prateek Kumar Panda, Department of Pediatrics, AIIMS, New Delhi
}

Corresponding Author: Prateek Kumar Panda, Department of Pediatrics, AIIMS, New Delhi, Email: drprateekpanda@gmail.com

\begin{abstract}
Autism spectrum disorder (ASD) usually presents in early developmental period, in children less than five years usually with poor social relations, verbal and nonverbal communications and stereotypic and repetitive behavior. The prevalence of ASD is increasing rapidly; especially in urban community of developed as well as developing nations. Combined interaction of genetic and environmental factors has been proposed as the possible neuropathogenetic mechanism underlying ASD. Children with ASD have specific abnormalities in functional connectivity of brain and altered fecal microbiota. Children with Fragile $\mathrm{X}$ syndrome, Rett syndrome and Tuberous sclerosis often have autistic features.Interviewing the caregiver and observation of the child is the only definitive way to confirm the diagnosis of ASD. Recently DSM V criteria have combined under a single umbrella all the autistic disorders including Asperger syndrome and pervasive developmental disorder-not otherwise satisfied. Apart from DSM V criteria, Autism Diagnostic Observation Schedule (ADOS) and Childhood Autism Rating Scale (CARS) are also useful in diagnosis and evaluation of children with ASD. Autistic children are more likely to have hyperactivity, inattention, sleep abnormalities and epilepsy, as compared to general population. Applied behavioral analysis, sensory integration therapy and structured teaching are used in the management of autism spectrum disorder, along with atypical antipsychotics like Risperidone and Aripiprazole. Various complementary and alternative treatments like music therapy, oral probiotics and gluten free, casein free diet are currently under evaluation in various clinical studies.
\end{abstract}

Key words: Autism spectrum disorder; Children; Applied behavioral analysis; Childhood autism rating scale; Social communication

\section{What is Autism?}

Autism spectrum disorder (ASD) is a complex neurodevelopmental condition with lifelong impacts, currently emerging as a global pandemic, surrounded by plenty of myths and mysteries [1]. It is characterized by persistent deficiencies in social communication and interaction across settings, restricted and repetitive behaviors, interests, or activities, along with onset in early development period and symptoms limiting and impairing daily functioning [2].

\section{Health care burden of Autism}

In India, estimated prevalence of autism is $1.12(0.74-$ 1.68) per 100 children [INCLEN study]. Incidence of Autism spectrum disorder in males is 1:42 whereas in females it is about 1:189 [3]. This makes that every 1 in 68 children are diagnosed with autism spectrum

Manuscript received: $5^{\text {th }}$ March 2019

Reviewed: $14^{\text {th }}$ March 2019

Author Corrected: $19^{\text {th }}$ March 2019

Accepted for Publication: $24^{\text {th }}$ March 2019 disorder, leading to a considerable health care and economic burden on society. Thus approximately four males are affected with ASD for every female, though the sex ratio appears to decrease with increasing severity [4].

\section{Gender disparity and familial predisposition}

Although this pronounced sex disparity is found in all populations studied and has been historically consistent, differences in symptom presentation in females and potential attendant diagnostic biases, even though unlikely to fully explain observed differences, are worthy of additional investigation [5].

Risk in siblings is around $7 \%$ if the affected child is a girl and $4 \%$ if the affected child is a boy. If a second child has Autism, risk increases to $25-35 \%$. Almost 2$3 \%$ of families have more than one affected children [6]. 
Review Article

Advanced paternal age, higher socioeconomic status of parents and nuclear family have been proposed as plausible risk factors for autism, but definitive evidence regarding risk factors is lacking and large population studies can only reveal these hidden risk factors [7].

\section{Clinical features of autism}

Onset of ASD symptoms typically occurs by age 3, although symptoms may not fully manifest until school age or later, and some research suggests symptoms can emerge between 6 and 18 months of age [8]. More severely affected children are more likely to be identified and reliably diagnosed at younger ages than milder cases. Early markers of autism are no babbling by 12 months, not waving bye-bye by 12 months, no single words by 16 months, no two-word spontaneous (not just echolalic) phrases by 24 months and loss of any language or social skills at any age [9].

\section{Co-morbidities of Autism}

Common co-morbidities associated with Obsessive compulsive behavior, intellectual disability, epilepsy, vision \& hearing problems, behavioral disorders, feeding disturbances, sleep disturbances, abnormalities of mood, sensory deviance and hyperactivity. 40 to $80 \%$ of children with autism spectrum disorder have sleep problems like difficulty going off to sleep, frequent awakenings and decrease in total sleep time [10]. These co-morbidities can be often treated to modify the natural course of autism and symptomatic relief to the children

Melatonin can be used to reduce sleep onset latency in children with sleep disturbance, along with sleep hygiene [11]. Hyperactivity and disruptive behavior are often controlled with careful titration of atypical antipsychotics like Risperidone and Aripiprazole [12]. Epilepsy or even epileptiform discharges in EEG without clinical eizure warrant antiepileptic drugs.

\section{Neuropathogenesis of Autism}

Autism is broadly considered to be a multi-factorial disorder resulting from genetic and non-genetic risk factors and their interaction. Genetic studies of ASD have identified mutations and copy number variants, as well as specific genetic locus that interfere with typical neurodevelopment in utero through childhood. These complexes of genes have been involved in synaptogenesis and axon motility [13]. Genetic studies have also identified also the importance of single nucleotide polymorphisms, epigenetics i.e. geneenvironment interactions [14]. Epidemiologic investigations focused on nongenetic factors have established advanced parental age and preterm birth as ASD risk factors, indicated that prenatal exposure to air pollution might be a potential risk factors, and suggested the need for further exploration of certain prenatal nutrients, metabolic conditions, and exposure to endocrine-disrupting chemicals [15].

\section{Functional MRI and other neuroimaging abnormalities}

Recent developments in neuroimaging studies have provided many important insights into the pathological changes that occur in the brain of patients with ASD in vivo [16]. Especially, the role of amygdala, a major component of the limbic system and the affective loop of the cortico-striatothalamo-cortical circuit, in cognition and ASD has been proved in numerous neuropathological and neuroimaging studies [17].

Besides the amygdala, the nucleus accumbens is also considered as the key structure which is related with the social reward response in ASD. Different proposed mechanisms include abnormal connectivity amongst the brain cells called neurons, defect in brain formation in a fetus at the microscopic level, neurotransmitter imbalance and abnormal mirror neurons.

\section{Specific genetic syndromes associated with ASD}

Up to $10 \%$ of cases can be linked to a known genetic cause via monogenic syndromes (such as fragile $\mathrm{X}$ syndrome, Tuberous sclerosis, and Rett syndrome) [18]. Apart from these, children with cerebral creatine deficiency, deletion on $15 \mathrm{q}$ chromosome, velocardiofacial syndrome, William Beuren syndrome, PTEN mutation and Neurofibromatosis type 1 often have autistic features. Children with various epileptic encephalopathies and intractable epilepsy, such as Dravet syndrome and Lennox Gastut syndrome may develop autistic features, along with cognitive impairment [18].

\section{How to diagnose autism?}

A clinical diagnosis of ASD relies on expert judgment to detect significant impairment in the core behavioral domains. No biochemical or radiological investigations can establish the diagnosis of ASD. In 2013, the fifth revision of the Diagnostic and Statistical Manual of Mental Disorders (DSM-5) changed ASD diagnostic criteria, eliminating diagnostic subtypes (which had included autistic disorder, Asperger's syndrome, and Pervasive Developmental Disabilities-Not Otherwise Specified) and creating a single category formally designated as ASD. Rett syndrome is now excluded from the DSM-5 criteria of ASD [19]. 


\section{Different tools used for diagnosing and evaluating severity of ASD}

Standardized research assessment tools, most notably the Childhood Autism Rating Scale (CARS), Autism Diagnostic Observation Schedule (ADOS), Autism Diagnostic Interview-Revised (ADI-R), Autism Treatment Evaluation Checklist (ATEC) and Autism Behavior Checklist (ABC) are used to further elaborate the symptomatology and severity of autistic features of the child. In western world, ADOS and ADI-R are considered gold standard for children with autism. However, in developing countries DSMV criteria for ASD, along with INDT tool can be used to diagnose ASD with excellent sensitivity and specificity [20].

\section{DSM V criteria for Autism spectrum Disorder}

It was first proposed in 2013 [21]. In these criteria, diagnosis of ASD is based on 2 areas: deficits in social communication and fixated interests and repetitive behavior. Restriction of onset age was also loosened from 3years to "early developmental period". New severity ranking was also introduced based on level of support and social impairment of the children. The DSM-5 combined previously distinct social and communication deficit criteria into one domain and incorporated a severity rating. It has also added a new diagnosis, social communication disorder (SCD), outside of ASD [21].

\section{INDT (INCLEN diagnostic tool for Autism) tool and ISAA (Indian Scale for Severity of Autism)}

INDT tool and ISAA have been used in India for diagnosing and calculating severity of autism for disability certification in our country. An AIIMS modified Diagnostic tool for ASD has been developed and validated, with good psychometric properties recently and also a freely downloadable mobile app has been developed based on this tool to help physicians in the diagnosis of autism [22]. Investigations like MRI brain, EEG, karyotyping, MLPA/CMA and whole exome sequencing are catered to children as required, to find out the underlying etiology and autism mimics, but an all inclusive shotgun approach should be avoided [23]. Holistic management of autism requires help from multiple specialties like Pediatric Neurologist, Clinical Psychologist, Geneticist, Special educator, occupational and speech therapist, along with empowering the caregivers, which is equally important [23].

\section{Childhood autism Rating Scale}

The Childhood Autism Rating Scale (CARS) is a behavior rating scal intended to help diagnose autism.
CARS was developed by Eric Schopler, Robert J. Reichier, and Barbara Rochen Renner. The scale was designed to help differentiate children with autism from those with other developmental delays, such as intellectual disability [24].

Although there is no gold standard among rating scales in detecting autism, CARS is frequently used as part of the diagnostic process. The CARS is a diagnostic assessment method that rates individuals on a scale ranging from normal to severe, and yields a composite score ranging from non-autistic to mildly autistic, moderately autistic, or severely autistic. The scale is used to observe and subjectively rate fifteen items [24].

\section{Autism Behavior Checklist}

The Autism Behavior Checklist (ABC) is a checklist of non-adaptive behaviors; capable of providing how an individual "Looks" in comparison to others. This checklist reflects an individual's challenges to respond appropriately to daily life situation. Parents and the educational team at school complete the check lists. Differences in behaviors were noted in the following areas: Sensory Behaviors, Relating Behaviors, Body and Object Use Behaviors and Language Behaviors [25].

\section{Autism mimics}

Certain conditions like Electrical Status Epilepticus in Sleep (ESES), Landau Kleffner Syndrome (LKS), certain autoimmune and paraneoplastic causes can mimic autism spectrum disorder [26]. Both LKS and CSWS (continuous spike and wave during slow wave sleep) can have ESES when EEG is done in these children. So whenever the hyperactivity or aggression is inappropriately high as compared to the severity of core symptoms, a sleep and awake EEG should be done [26].

\section{Electrical Status Epilepticus in Slow wave Sleep (ESES)}

Activation or potentiation of epileptiform discharges in sleep with near continuous, bilateral, or occasionally lateralized slow spikes and waves is called ESES [27]. Occurrence "during a significant proportion" of the non-REM sleep with a threshold ranging from $25 \%$ to $85 \%$ was previously a requirement, currently which is removed by International League against Epilepsy (ILAE) [27].

\section{Holistic management of children with autism}

Although educational and behavioral interventions have been the mainstay of the management of ASD, 
pharmacological treatments like Risperidone, Aripiprazole, Olanzapine, Melatonin, Clonidine, Methylphenidate, SSRI and Benzodiazepines have also shown some benefit in selected subjects with ASD, for treating the co-morbidities like hyperactivity, disruptive behavior, self-injurious behavior and sleep disturbances and also core features like stereotypies to some extent [28].

Modified applied Behavior Analysis, Individualized Structured Teaching Programme, sensory Integration Therapy and Parental Counseling and Training are evidence based interventions for autistic children, which are currently recommended [28].

\section{Applied behavior analysis (ABA)}

ABA is the process of applying interventions derived from experimental psychology research to systematically change behavior. These are based onthe principles of learning. This is the most recommended behavioral intervention for children with ASD. ABA can be used for all age groups and autism severity levels. Visual cues are better than verbal instruction for the children with autism. Several clinical studies from different parts of the world have proved the efficacy of ABA in children with autism [29].

\section{Special consideration for adolescents}

For preadolescents and adolescents, sexual and menstrual issues need to be entertained, along with proper inclusive education, vocational training and skill development [30].

Key points in training a child with Autism are to use visuals, avoid long strings of verbal instruction, to encourage development of child's special talents, to use child's fixations to motivate school work, to use concrete, visual methods to teach number concepts, to protect child from sounds that hurt his/her ears, to place child near a window and avoid using fluorescent lights, to interact with the child while he/she is swinging or rolled in a mat, to teach with tactile learning materials (e.g., sandpaper alphabet), to use printed words and pictures on a flash card [31].

\section{Complementary and Alternate Modalities (CAM) for treatment of Autism}

Various alternate and complementary therapies in Autism, which are still in investigational stage with ongoing research are Gluten Free Casein Free diet, vitamin B 12, folic acid, pyridoxine and other megavitamin doses, Omega 3 fatty acids, probiotics, Iron, chelation to treat heavy metal toxicity confirmed, ascorbic acid, acupuncture/massage/ exercise/ music therapy, hyperbaric oxygen and stem cell therapy [32]. Inappropriate widespread use of these therapies in all children with autism, without any definite medical indication may lead to more harm than benefit.

The key architecture of ASD development which could be a target for treatment is still an uncharted territory. Further research work is needed to broaden the horizons on the understanding of ASD [33]. Probiotics, music therapy and Gluten Free Casein Free diet have been found to be efficacious in few small RCTs from different parts of the world to be efficacious in children with autism [34].

\section{Screening tools for autism in young children}

Screening tools like M-CHAT (modified Check List for autism) is utilized to determine whether children of age 18-36 months are at risk of autism [35]. Early diagnosis and immediate institution of behavioral intervention often provides favorable outcome. Even the mothers of autistic children remember that during infancy these autistic children remained aloof, did not cuddle, had poor eye contact and did not show much interest in caregivers.

\section{Conclusion}

General physicians and pediatricians as well as child psychologists should be aware of the features of autism and also early markers of autism in young children for timely diagnosis. The caregivers should be guided properly after diagnosis with institution of applied behavior analysis, sensory integration therapy and structured teaching to optimize the clinical outcome in these children. Complementary and alternative treatments for autism should be used judiciously from case to case basis. Autism mimics and genetic causes should be ruled out in selected cases whenever clinical suspicion points towards some atypical features.

Funding: Nil, Conflict of interest: None initiated, Perission from IRB: Yes

\section{References}

1. Lewis AS, van Schalkwyk GI. Systematic Review: Distribution of Age and Intervention Modalities in Therapeutic Clinical Trials for Autism Spectrum Disorder.J Autism Dev Disord. 2019 Feb 27. doi: 10.10 07/s 10803-019-03942-0. [Epub ahead of print]

2.Lai MC, Lombardo MV, Baron- Cohen S. Autism. Lancet. 2014 Mar 8;383(9920): 896-910. doi: 10.1016/ S0140-6736(13)61539-1. Epub 2013 Sep 26. 
Review Article

3. Baio J, Wiggins L, Christensen DL, et al. Prevalence of Autism Spectrum Disorder Among Children Aged 8 Years- Autism and Developmental Disabilities Monitoring Network, 11 Sites, United States, 2014. MMWR Surveill Summ. 2018 Apr 27; 67(6):1-23. doi: 10.15585/mmwr.ss6706a1.

4. Shi HF, Zhang JX, Zhang R, et al. [Prevalence of autism spectrum disorders in children aged 0-6 years in China: a meta-analysis]. Beijing Da Xue Xue Bao Yi Xue Ban. 2017 Oct 18;49 (5):798-806.

5. Wang C, Geng H, Liu W, et al. Prenatal, perinatal, and postnatal factors associated with autism: A metaanalysis. Medicine (Baltimore). 2017 May; 96 (18): e6696. doi: 10.1097/MD.0000000000006696.

6. Wu S, Wu F, Ding Y, et al. Advanced parental age and autism risk in children: a systematic review and meta-analysis. Acta Psychiatr Scand. 2017 Jan;135(1): 29-41. doi: 10.1111/acps.12666. Epub 2016 Nov 14.

7. Gardener H, Spiegelman D, Buka SL. Perinatal and neonatal risk factors for autism: a comprehensive metaanalysis. Pediatrics. 2011 Aug;128(2):344-55. doi: 10.1542/peds.2010-1036. Epub $2011 \mathrm{Jul} 11$.

8. Izuwah DN, Okoh BA, AlikorEA. Clinical Pattern of Autism in Nigeria. Autism Res. 2016 Mar;9(3):376-81. doi: 10.1002/aur.1531

9. Grapel JN, Cicchetti DV, Volkmar FR. Sensory features as diagnostic criteria for autism: sensory features in autism..Yale J Biol Med. 2015 Mar 4;88(1):69-71

10. Pitzianti M, D'Agati E, Pontis M, et al. Comorbidity of ADHD and High-functioning Autism: A Pilot Study on the Utility of the Overflow Movements Measure. J Psychiatr Pract. 2016 Jan;22 (1): 22-30. doi: 10.1097/PRA. 00000000000-00120.

11. Mazurek MO, Dovgan K, Neumeyer AM, et al. Course and Predictors of Sleep and Co-occurring Problems in Children with Autism Spectrum Disorder. J Autism Dev Disord. 2019 May;49(5):2101-2115. doi: 10.1007/s10803-019-03894-5.

12. Besag F, Gobbi G, Aldenkamp A, et al. Psychiatric and Behavioural Disorders in Children with Epilepsy (ILAE Task Force Report): Behavioural and psychiatric disorders associated with childhood epilepsy syndromes. Epileptic Disord. 2016 May 16. [Epub ahead of print] DOI:10.1684/epd.2016.0815
13. Stefano V, Eleonora N, Viviana C, Deny M, Viola A, Sara L, Antonio N, Marco T. Copy number variants in autism spectrum disorders. Prog Neuropsychopharmacol Biol Psychiatry. 2019 Feb 20. pii: S02785846 (18) 30502-5. doi: 10.1016/j.pnpbp.2019.02.012

14. Vorstman JAS, Parr JR, Moreno-De-Luca D, et al. Autism genetics: opportunities and challenges for clinical translation. Nat Rev Genet. 2017 Jun;18(6):362376. doi: 10.1038/nrg.2017.4. Epub 2017 Mar 6.

15. Paysour MJ, Bolte AC, Lukens JR.Crosstalk Between the Microbiome and Gestational Immunity in Autism-Related Disorders. DNA Cell Biol. 2019 Feb 28. doi: 10.1089/dna.2019.4653. [Epub ahead of print]

16. Gabrielsen TP, Anderson JS, Stephenson KG, et al. Functional MRI connectivity of children with autism and low verbal and cognitive performance. Mol Autism. 2018 Dec 27;9:67. doi: 10.1186/s13229-0180248-y. eCollection 2018.

17. Cheng W, Rolls ET, Zhang J, et al. Functional connectivity decreases in autism in emotion, self, and face circuits identified by Knowledge-based Enrichment Analysis. Neuroimage. 2017 Mar 1;148:169-178. doi: 10. 1016/j.neuroimage.2016.12.068. Epub 2016 Dec 28.

18. Chaste P, Leboyer M. Autism risk factors: genes, environment, and gene-environment interactions. Dialogues Clin Neurosci. 2012 Sep;14 (3):281-92.

19. Miller LE, Burke JD, Robins DL, et al. Diagnosing Autism Spectrum Disorder in Children with Low Mental Age. J Autism Dev Disord. 2019 Mar;49 (3):1080-1095. doi: 10.1007/s10803-018-3810-8.

20. Mattila ML, Kielinen M, Linna SL, et al. Autism spectrum disorders according to DSM-IV-TR and comparison with DSM-5 draft criteria: an epidemiological study. J Am Acad Child Adolesc Psychiatry. 2011 Jun;50(6):583-592.e11.doi:10.1016/j.jaac. 2011.04.001.

21. Lord C, Bishop SL. Recent advances in autism research as reflected in DSM-5 criteria for autism spectrum disorder. Annu Rev Clin Psychol. 2015;11:5370. doi: 10.1146/annurev-clinpsy-032814-112745. Epub 2015 Jan 2.

22. Juneja M, Mishra D, Russell PS, et al. INCLEN Diagnostic Tool for Autism Spectrum Disorder (INDTASD):development and validation. Indian Pediatr. 2014 May; 51(5):359-65. 
Review Article

23. Vats P, Juneja M, Mishra D. Diagnostic Accuracy of International Epidemiology Network (INCLEN) Diagnostic Tool for Autism Spectrum Disorder (INDTASD) in Comparison with Diagnostic and Statistical Manual of Mental Disorders-5 (DSM-5). Indian Pediatr. 2018 Jun 15;55(6):482-484.

24. Dawkins T1, Meyer AT2, Van Bourgondien ME. The Relationship Between the Childhood Autism Rating Scale: Second Edition and Clinical Diagnosis Utilizing the DSM-IV-TR and the DSM-5. J Autism Dev Disord. 2016 Oct;46(10):3361-8. doi: 10.1007/ s10803-016-2860-z.

25. Limberg K1, Gruber K2, Noterdaeme M. The German version of the Child Behavior Checklist 1.5-5 to identify children with a risk of autism spectrum disorder. doi: 10.1177/1362361316645932. Epub 2016 Jul 9.

26. Gencpinar P, Dundar NO, Tekgul H. Electrical status epilepticus in sleep (ESES)/continuous spikes and waves during slow sleep (CSWS) syndrome in children: An electroclinical evaluation according to the EEG patterns. Epilepsy Behav. 2016 Aug; 61:107-111. doi: 10.1016/j.yebeh. 2016.05.014. Epub 2016 Jun 21.

27. Kotagal P. Current Status of Treatments for Children with Electrical Status in Slow-Wave Sleep (ESES/CSWS). Epilepsy Curr. 2017 Jul-Aug;17(4): 214-216. doi: 10.5698/1535-7597.17.4.214.

28. Sanchack KE, Thomas CA. Autism Spectrum Disorder: Primary Care Principles. Am Fam Physician. 2016 Dec 15;94 (12):972-979.

29. Fuller EA, Kaiser AP. The Effects of Early Intervention on Social Communication Outcomes for Children with Autism Spectrum Disorder: A Meta-
analysis.J Autism Dev Disord. 2019 Feb 25. doi: 10.100 7/s10803-019-03927-z. [Epub ahead of print]

30. Fontil L, Gittens J, Beaudoin E, et al. Barriers to and Facilitators of Successful Early School Transitions for Children with Autism Spectrum Disorders and Other Developmental Disabilities: A Systematic Review. J Autism Dev Disord. 2019 Feb 26. doi: 10.1007/s10803019-03938-w. [Epub ahead of print]

31. Reinders NJ, Branco A, Wright K, Scoping Review: Physical Activity and Social Functioning in Young People With Autism Spectrum Disorder. Front Psychol. 2019 Feb 13;10:120. doi: 10.3389 /fpsyg. 2019. 00120. eCollection 2019.

32. Höfer J, Hoffmann F, Kamp-Becker I, et al. Complementary and alternative medicine use in adults with autism spectrum disorder in Germany: results from a multi-center survey. BMC Psychiatry. 2019 Feb 1;19 (1): 53. doi: 10.1186/s12888-019-2043-5.

33. Stegemann T, Geretsegger M, Phan Quoc E, et al. Music Therapy and Other Music-Based Interventions in Pediatric Health Care: An Overview. Medicines (Basel). 2019 Feb 14;6 (1). pii: E25. doi: 10.3390/ medicines6010025.

34. Kang DW, Ilhan ZE, Isern NG, et al. Differences in fecal microbial metabolites and microbiota of children with autism spectrum disorders. Anaerobe. 2018 Feb;49:121-131. doi: 10.1016/j.anaerobe. 2017.12.007. Epub 2017 Dec 22.

35. Dumont-Mathieu T, Fein D. Screening for autism in young children: The Modified Checklist for Autism in Toddlers (M-CHAT) and other measures. Ment Retard Dev Disabil Res Rev. 2005;11(3):253-62.

\section{How to cite this article?}

Panda P. Current consensus on clinical features, pathogenesis, diagnosis and management of autism spectrum disorder in children: A brief review. Int J Pediatr Res. 2019;6(03):144-149.doi:10.17511/ijpr.2019.i03.07 